\title{
The effect of three types of saponin on iron and zinc absorption from a single meal in the rat
}

\author{
By SUSAN SOUTHON, A. J. A. WRIGHT, K. R. PRICE, \\ S. J. FAIRWEATHER-TAIT AND G. R. FENWICK \\ AFRC Institute of Food Research, Norwich Laboratory, Colney Lane, Norwich NR4 $7 U A$
}

(Received 20 August 1987 - Accepted 8 December 1987)

1. Iron and zinc retentions in young male rats, given $3 \mathrm{~g}$ starch-sucrose paste containing $120 \mu \mathrm{g} \mathrm{Fe}$ as $\mathrm{FeSO}_{4}$ or $139 \mu \mathrm{g} \mathrm{Zn}$ as $\mathrm{ZnCl}_{2}$ (extrinsically labelled with ${ }^{59} \mathrm{Fe}$ or ${ }^{65} \mathrm{Zn}$ ) and increasing amounts of Gypsophila saponins, were measured by whole-body counting. The results were compared with whole-body $\mathrm{Fe}$ and $\mathrm{Zn}$ retention from a meal containing crude or purified saponin fractions. In a separate experiment Fe retention from a meal containing Gypsophila saponins, soyasaponin I, or saponins extracted from lucerne (Medicago sativa) plant tops, was measured in older rats.

2. Results indicated that Fe absorption decreased with increasing concentration of Gypsophila saponins. This was significant at a saponin: Fe molar value of approximately 1, with maximum effect occurring at molar ratios of 4 and above, when Fe absorption was reduced by approximately $17 \%$. Gypsophila saponins had no effect on $\mathrm{Zn}$ absorption from a test meal.

3. Fe absorption was similar in groups given purified or crude Gypsophila saponins at the same saponin: mineral molar value of 8 , demonstrating that the 'non-saponin' fraction of the commercial preparation does not affect the absorption of this mineral.

4. Saponins extracted from lucerne plant tops, fed at a saponin:Fe value of approximately 8 , also reduced $\mathrm{Fe}$ absorption from a single meal. Fe absorption from a meal containing a similar amount of soyasaponin I was not significantly different from controls.

5. These results indicate that some dietary saponins may reduce $\mathrm{Fe}$ absorption and hence have an adverse effect on Fe status in man and simple-stomached animals.

It has been demonstrated recently that the consumption of a semi-synthetic diet containing $12 \mathrm{~g}$ Gypsophila saponins/kg for a 3 week period, had a detrimental effect on iron status in growing rats (Southon et al. 1988). In view of this finding, and the suggestion that the consumption of saponins by man should be encouraged as a means of reducing hypercholesterolaemia (Malinow et al. 1980), the present study was undertaken to investigate this effect in greater detail.

The haemolytic properties of saponins are well-known but the normal environment of the erythrocytes counteracts much of their haemolytic activity and it is generally agreed that they are not readily absorbed (Bondi et al. 1973; Cheeke, 1980). It is more likely, therefore, that the lower Fe status observed in rats consuming saponins was a consequence of reduced $\mathrm{Fe}$ absorption, rather than metabolic disturbances caused by saponins entering the bloodstream.

In the present study the effect of saponins on $\mathrm{Fe}$ absorption was investigated by measuring whole-body ${ }^{59} \mathrm{Fe}$ retention in rats from a single test meal containing extrinsicallylabelled ferrous sulphate, together with varying amounts of saponins. The effect of saponins on zinc absorption from zinc chloride, extrinsically labelled with ${ }^{65} \mathrm{Zn}$, was also investigated using a similar technique. The three saponins used in the present study were a commercially available 'non-food' saponin extracted from the roots of Gypsophila sp., soyasaponin I which is the dominant saponin found in most legumes (Price et al. 1986) and therefore consumed in significant quantities by man, and saponin extracted from lucerne (Medicago sativa; commonly called alfalfa) plant tops which are more usually consumed by animals. 


\section{MATERIALS AND METHODS}

Three experiments were performed, the first to determine whether there was any indication that Gypsophila saponins influenced $\mathrm{Fe}$ absorption from a meal at low saponin: Fe molar values, and the second at higher saponin: Fe molar values. Test meals given to rats in Expts 1 and 2 contained saponin:Fe molar values of $0 \cdot 5,1,2$ and 4 , and 8,16 and 32 respectively. The first experiment also included an investigation of $\mathrm{Zn}$ absorption from meals containing saponin. Test meals contained either untreated crude saponin ('saponin white') obtained from Sigma Chemical Co. Ltd, Poole, or crude saponin which had been purified by means of reversed-phase flash chromatography as previously described (Price et al. 1987; Southon et al. 1988). Quantitative analysis of the commercially supplied material demonstrated that it contained $604 \mathrm{~g}$ saponin $/ \mathrm{kg}$ dry weight.

In the third experiment $\mathrm{Fe}$ absorption from meals containing different saponins was measured. Gypsophila saponins, soyasaponin I or saponins extracted from lucerne plant tops, given at a saponin:Fe molar value of approximately 8, were studied. Soyasaponin I was isolated from lucerne seeds according to the method patented by Kitagawa (1984). The isolated saponin was shown to be homogenous by thin-layer chromatography (TLC) using two solvent systems. The saponins present in lucerne plant tops were extracted from the tissue according to the method of Gestetner (1971). The saponin fraction was shown to be homogenous by TLC. Detailed information on the occurrence and probable structures of these saponins has been presented in a recent review (Price et al. 1987).

\section{Expt 1}

Male Wistar rats (120), weighing approximately $80 \mathrm{~g}$, were given a control (saponin-free) semi-synthetic diet for $9 \mathrm{~d}$, and trained to meal-feed in the final $2 \mathrm{~d}$. The diet was of similar composition to that described previously (Fairweather-Tait \& Wright, 1984) with the addition of $2.5 \mathrm{~g}$ methionine $/ \mathrm{kg}$ diet. Rats were allocated to twelve groups of ten, with similar mean body-weights, fasted overnight and each animal given a test meal of $3 \mathrm{~g}$ cooked starch-sucrose $(1: 1, \mathrm{w} / \mathrm{w})$ paste containing either $120 \mu \mathrm{g} \mathrm{Fe}$ as ferrous sulphate in $0.1 \mathrm{~m}$-hydrochloric acid, labelled with $18.5 \mathrm{kBq}{ }^{59} \mathrm{Fe}\left(\mathrm{FeCl}_{3}, 110-740 \mathrm{MBq} / \mathrm{mg} \mathrm{Fe}\right.$, Amersham International, Amersham, Bucks) or $139 \mu \mathrm{g} \mathrm{Zn}$ as zinc chloride in $0.1 \mathrm{M}-\mathrm{HCl}$, labelled with $37 \mathrm{kBq}{ }^{65} \mathrm{Zn}\left(\mathrm{ZnCl}_{2}, 3 \cdot 7-92.5 \mathrm{MBq} / \mathrm{mg} \mathrm{Zn}\right.$, Amersham International).

Fe absorption was measured in the first six groups, the saponin content of the meals being as follows: group 1, no added saponin; groups 2, 3, 4 and 5, purified Gypsophila saponins in saponin:Fe molar ratios of $0.5,1,2$ and 4 respectively; group 6 , crude Gypsophila saponins in a saponin:Fe molar ratio of 0.5 (assuming a molecular weight of 1500 for the saponins and a purity of $604 \mathrm{~g} / \mathrm{kg}$ for the crude saponin extract).

$\mathrm{Zn}$ absorption was measured in the remaining six groups. Test meals were prepared to give saponin: $\mathrm{Zn}$ molar ratios similar to the saponin: $\mathrm{Fe}$ molar ratios used in the $\mathrm{Fe}$ absorption study.

In all three experiments, the control semi-synthetic diet was provided ad lib. $4 \mathrm{~h}$ after the test meal until the end of the experiment.

\section{Expt 2}

Fifty male Wistar rats, weighing approximately $60 \mathrm{~g}$, were given a semi-synthetic diet for $10 \mathrm{~d}$. Rats were trained to meal-feed during the final $3 \mathrm{~d}$ of this period and then allocated to five groups of ten such that the mean body-weights of the groups were similar. After an overnight fast, each animal was given a $3 \mathrm{~g}$ starch-sucrose test meal containing $120 \mu \mathrm{g} \mathrm{Fe}$ labelled with ${ }^{59} \mathrm{Fe}$ and an appropriate amount of Gypsophila saponins. Group 1 received a meal with no added saponin; groups 2, 3 and 4 were given purified saponins in amounts 
calculated to give saponin:Fe molar ratios of approximately 8,16 and 32 respectively; group 5 was given crude Gypsophila saponins at a saponin:Fe molar value of 8 .

\section{Expt 3}

Sixty male Wistar rats, weighing approximately $200 \mathrm{~g}$, were given a semi-synthetic diet for $14 \mathrm{~d}$ and trained to meal feed in the final $2 \mathrm{~d}$ of this period. Rats were allocated to four groups of fifteen, with similar mean body-weights and, after an overnight fast, given a ${ }^{59} \mathrm{Fe}$-labelled test meal as described in Expt 2 . The type of saponin added to each meal was as follows: group 1, no added saponin; group 2, soyasaponin I; group 3, lucerne-plant-top saponins; group 4, Gypsophila saponins. Meals given to rats in groups 2, 3 and 4 each contained $16 \mathrm{mg}$ saponin, giving a saponin:Fe molar ratio of approximately 8 , assuming a molecular weight of 1000 for each of the saponins.

\section{Whole-body counting}

Whole-body radioactivity was measured using a NE 8112 small animal whole-body counter (Nuclear Enterprises, Edinburgh) as described by Fairweather-Tait \& Wright (1984).

Whole-body $\mathrm{Fe}$ retention was calculated by measuring the ${ }^{59} \mathrm{Fe}$ content of the whole body immediately post-dosing and again $7 \mathrm{~d}$ later when all the unabsorbed $\mathrm{Fe}$ from the test meal had been excreted. The amount of ${ }^{59} \mathrm{Fe}$ remaining at this time was taken to be an estimate of Fe absorption from the meal (Fairweather-Tait \& Wright, 1984).

$\mathrm{Zn}$ absorption was estimated by counting the animals immediately after consuming the meal, and then 5, 7,9 12 and $13 \mathrm{~d}$ after the dosing; it was assumed that all the unabsorbed ${ }^{65} \mathrm{Zn}$ would be excreted within $5 \mathrm{~d}$ of dosing. The counts obtained at each time point (after correcting for counting efficiency, background and decay) were expressed as a percentage of the counts present in the animal immediately after consuming the test meal to give wholebody retention (apparent absorption). The logarithm of the percentage whole-body retention at each time point was plotted against time, and from regression analysis an estimate of true ${ }^{65} \mathrm{Zn}$ absorption from the meal was obtained. This technique makes allowances for endogenous losses of ${ }^{65} \mathrm{Zn}$ over the experimental period (Heth \& Hoekstra, 1965).

\section{Statistical analysis}

Both regression and one-way analysis of variance were performed using the statistical package GENSTAT (Alvey et al. 1977). Where analysis of variance showed a treatment effect, approximate $t$ tests between two means $\left(x_{1}\right.$ and $\left.x_{2}\right)$ having $n$ replicates $\left(n_{1}\right.$ and $\left.n_{2}\right)$ were performed using the standard error of the difference of the means (SED) calculated from the residual mean square (RMS) (SED $={ }^{\prime}$ RMS. $\left.\left(\left(1 / n_{1}\right)+\left(1 / n_{2}\right)\right) ; t=\left(x_{1}-x_{2}\right) / \mathrm{SED}\right)$. The residual degrees of freedom used to estimate the level of significance of $t$ are shown in the appropriate tables of results.

\section{RESULTS}

Expt 1

Mean values for $\mathrm{Fe}$ absorption (\% of dose), in rats weighing 139 (SEM 1) g, from $120 \mu \mathrm{g}$ $\mathrm{Fe}$ in a test meal of $3 \mathrm{~g}$ cooked starch-sucrose paste, containing saponin:Fe molar values of approximately $0.5,1,2$ and 4 are shown in Table 1 . Animals that ate less than two-thirds of the meal were excluded from the experiment to minimize the possibility of a dose-related response (Bannerman et al. 1962). Results indicated that Fe absorption decreased with increasing concentration of Gypsophila saponins, the effect becoming significant at a saponin: $\mathrm{Fe}$ value of 1 . No significant reduction in ${ }^{59} \mathrm{Fe}$ absorption was observed at a saponin: Fe value of $0 \cdot 5$, for either the purified or crude extracts. 
Table 1. Expt $1 .{ }^{59} \mathrm{Fe}$ and ${ }^{65} \mathrm{Zn}$ absorption in rats from a $3 \mathrm{~g}$ starch-sucrose $(1: 1, \mathrm{w} / \mathrm{w})$ test meal containing $120 \mu \mathrm{g} \mathrm{Fe}$ or $139 \mu \mathrm{g} \mathrm{Zn}$ and variable amounts of Gypsophila saponins

(Values are means with their standard errors for the no. of observations indicated)

\begin{tabular}{|c|c|c|c|c|c|c|}
\hline \multirow{2}{*}{$\begin{array}{l}\text { Saponin: } F e \text { or } \mathrm{Zn} \\
\text { molar value }\end{array}$} & \multicolumn{3}{|c|}{${ }^{59} \mathrm{Fe}$ absorption (\% of dose) } & \multicolumn{3}{|c|}{${ }^{65} \mathrm{Zn}$ absorption ( $\%$ of dose) } \\
\hline & $n$ & Mean & SE & $n$ & Mean & SE \\
\hline 0 & 8 & $69 \cdot 9$ & $1 \cdot 4$ & 10 & $44 \cdot 8$ & 1.9 \\
\hline 0.5 & 10 & $67 \cdot 1$ & 1.9 & 10 & $44 \cdot 0$ & $2 \cdot 3$ \\
\hline $0.5 \dagger$ & 10 & $69 \cdot 4$ & $2 \cdot 0$ & 10 & $44 \cdot 1$ & 3.6 \\
\hline 1 & 10 & $63.8^{*}$ & $1 \cdot 6$ & 10 & $51 \cdot 3$ & $2 \cdot 2$ \\
\hline 2 & 10 & $62 \cdot 5^{*}$ & 1.3 & 9 & $45 \cdot 5$ & $3 \cdot 3$ \\
\hline 4 & 10 & $58 \cdot 2 * * *$ & $3 \cdot 0$ & 9 & $41 \cdot 7$ & $4 \cdot 4$ \\
\hline \multicolumn{2}{|l|}{ Residual mean square } & \multicolumn{2}{|l|}{37.95} & \multicolumn{3}{|c|}{ NA } \\
\hline \multicolumn{2}{|l|}{ Residual df } & \multicolumn{2}{|l|}{52} & & \multicolumn{2}{|l|}{ NA } \\
\hline
\end{tabular}

NA, not applicable as variance ratio $(F)$ for one-way analysis of variance was not significant at $P<0.05$.

Values within a vertical column were significantly different from the control group (saponin : Fe molar value 0 ): ${ }^{*} P<0.05,{ }^{* * *} P<0.00$ 1 (for details of statistical treatment, see p. 391).

$\dagger$ Crude saponin extract; purified saponins were given in all other test meals.

Table 2. Expt 2. ${ }^{59} \mathrm{Fe}$ absorption in rats from a $3 \mathrm{~g}$ starch-sucrose $(1: 1, w / w)$ test meal containing $120 \mu \mathrm{g} \mathrm{Fe}$ and variable amounts of Gypsophila saponin

(Values are means with their standard errors for the no. of observations indicated)

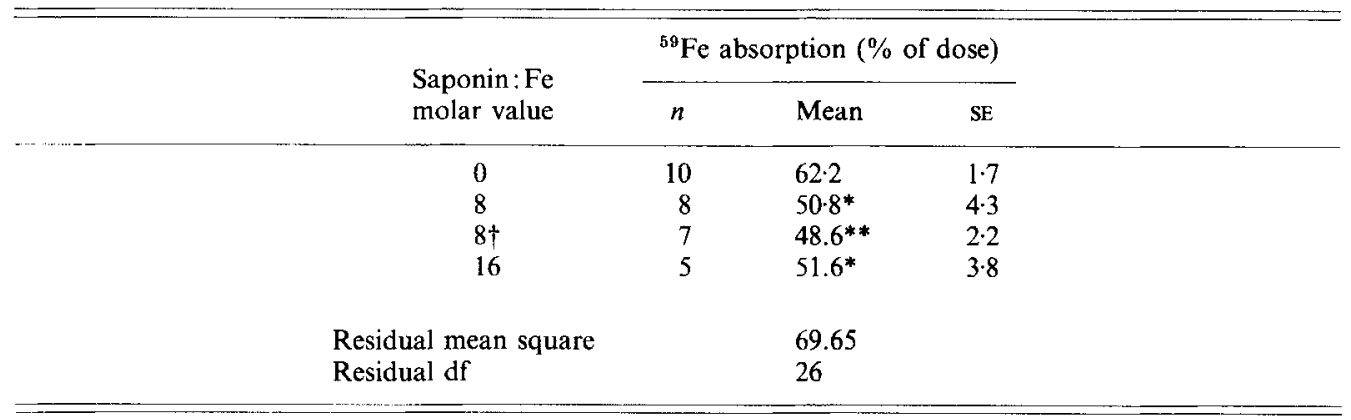

Values within a vertical column were significantly different from the control group (saponin: Fe molar value 0): ${ }^{*} P<0.05,{ }^{* *} P<0.01$ (for details of statistical treatment, see p. 391).

$\neq$ Crude saponin extract; purified saponins were given in all other test meals.

Gypsophila saponins had no effect on $\mathrm{Zn}$ absorption from the test meal, as shown in Table 1.

\section{Expt 2}

Values for $\mathrm{Fe}$ absorption (\% of dose), in rats weighing 113 (SEM 1) g, from test meals containing saponin:Fe molar values of 8 and 16 are shown in Table 2. At higher levels of Gypsophila saponins the test meals were obviously increasingly unpalatable and all animals from group 4 (saponin: Fe 32) had to be excluded, as less than two-thirds of the test meal had been consumed by each rat. However, there were sufficient numbers in the other groups 


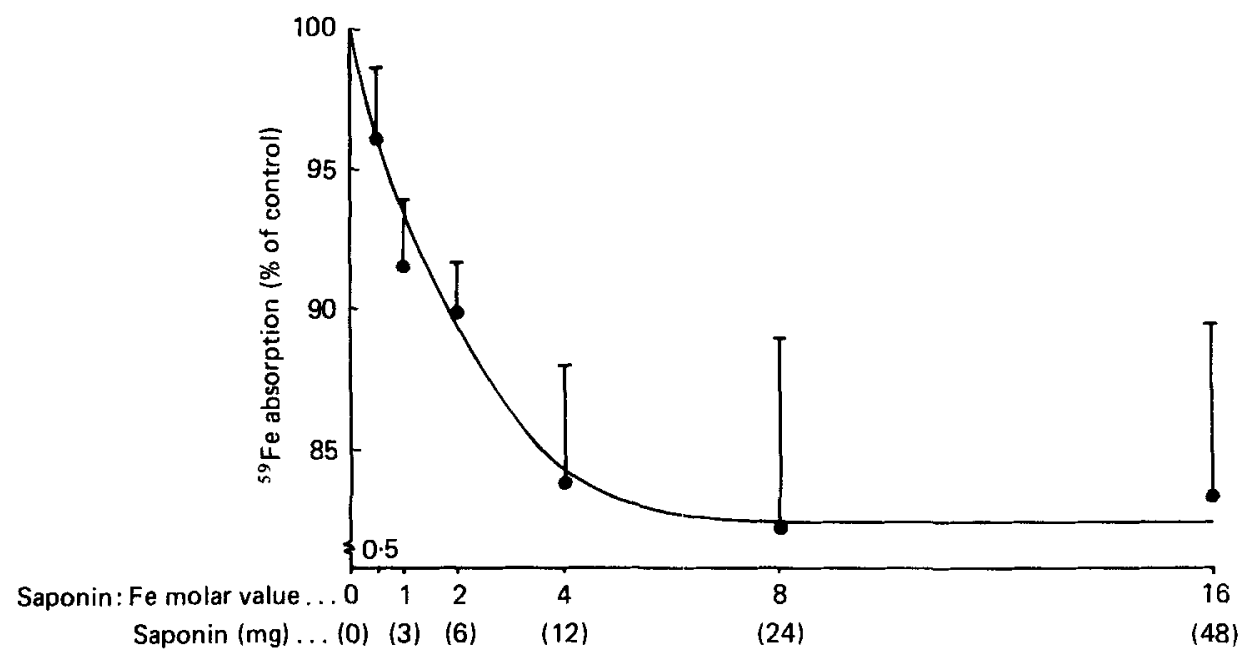

Fig. 1. Percentage ${ }^{59} \mathrm{Fe}$ absorption, relative to the mean absorption of the appropriate saponin-free control group, from $3 \mathrm{~g}$ starch-sucrose $(1: 1, \mathrm{w} / \mathrm{w})$ paste containing $120 \mu \mathrm{g} \mathrm{Fe}, 18.5 \mathrm{kBq}{ }^{58} \mathrm{Fe}$ and varying amounts of purified Gypsophila saponin. Results are plotted $v$. saponin:Fe molar values and absolute amounts of saponin. Points are mean values with their standard errors represented by vertical bars.

Table 3. Expt 3. ${ }^{59} \mathrm{Fe}$ absorption in rats from a $3 \mathrm{~g}$ starch-sucrose $(1: 1, w / w)$ test meal containing $120 \mu \mathrm{g} \mathrm{Fe}$ and $16 \mathrm{mg}$ soyasaponin I, lucerne (Medicago sativa)-plant-top saponins or Gypsophila saponins (saponin:Fe molar value aproximately 8)

(Values are means with their standard errors for the no. of observations indicated)

\begin{tabular}{|c|c|c|c|}
\hline \multirow{2}{*}{$\begin{array}{l}\text { Type of saponin } \\
\text { in test meal }\end{array}$} & \multicolumn{3}{|c|}{${ }^{59} \mathrm{Fe}$ absorption ( $\%$ of dose) } \\
\hline & $n$ & Mean & SE \\
\hline Control (no added saponin) & 15 & $64 \cdot 0$ & $1 \cdot 5$ \\
\hline Soyasaponin I & 14 & $59 \cdot 1$ & $2 \cdot 5$ \\
\hline Lucerne & 11 & $53 \cdot 4^{* * *}$ & 1.7 \\
\hline Gypsophila & 12 & $49 \cdot 5 * * *$ & $2 \cdot 3$ \\
\hline \multirow{2}{*}{\multicolumn{2}{|c|}{$\begin{array}{l}\text { Residual mean square } \\
\text { Residual df }\end{array}$}} & \multicolumn{2}{|l|}{54.91} \\
\hline & & \multicolumn{2}{|l|}{48} \\
\hline
\end{tabular}

Values within a vertical column were significantly different from the control group (saponin: Fe molar value 0 ): ***P $P<0.001$ (for details of statistical treatment, see p. 391).

to demonstrate that rats fed on meals containing saponin absorbed significantly less ${ }^{59} \mathrm{Fe}$ than those given the 'saponin-free' meal, and that the crude and purified saponin extracts, fed at a saponin: Fe molar value of 8 , produced a similar reduction in ${ }^{59} \mathrm{Fe}$ absorption. Data from Expts 1 and 2 were expressed as \% $\mathrm{Fe}$ absorption relative to the appropriate control value, and combined to give an indication of the relation between the amount of saponin consumed and whole-body ${ }^{59} \mathrm{Fe}$ retention. The resulting curve indicates that the effect is saturable and that it reaches a maximum at a saponin: Fe value of approximately 4 , when Fe absorption was reduced by $17 \%$ (Fig. 1). 
Expt 3

${ }^{59} \mathrm{Fe}$ absorption from a meal containing $16 \mathrm{mg}$ purified Gypsophila saponins (saponin: $\mathrm{Fe}$ molar value of approximately 8 ) was once again shown to be significantly lower than that of controls (Table 3). The reduction in Fe absorption in the mature rats, weighing 319 (SEM 3) g, was similar to that observed in younger animals given meals containing a similar amount of saponins (Table 2).

Lucerne-plant-top saponins $(16 \mathrm{mg} / \mathrm{meal})$ also reduced ${ }^{59} \mathrm{Fe}$ absorption from a test meal, but the same quantity of soyasaponin I had no significant effect when compared with the control group (Table 3). However, the mean value for ${ }^{59} \mathrm{Fe}$ absorption for the soyasaponin I group was not significantly different from that for rats given lucerne saponins, and statistical comparison of percentage Fe absorption in the soyasaponin $\mathrm{I} v$. the "saponinfree' control group gave a $P$ value of $<0 \cdot 1$, indicating a marginal effect.

\section{DISCUSSION}

Saponins comprise a structurally diverse class of chemicals widely found in the plant kingdom (Price et al. 1987). They are characterized by the presence of a lipophobic aglycone (which may be neutral, acidic or, in the case of the potato glycoalkaloids, basic) and a lipophilic carbohydrate moiety or moieties. Whilst these contrasting lipophilic-lipophobic characteristics give saponins their surface-active properties (Gohtani et al. 1985), other properties (biological and chemical) are now seen to be very much dependent on individual structural requirements. Only relatively recently have chemical techniques enabled the nature and amounts of individual saponins in plant foods and feedstuffs to be determined reliably (Price et al. 1986; Ireland \& Dziedzic, 1987). Analyses have now clearly shown that saponins vary qualitatively and quantitatively with the plant species and its age, the part examined, and environmental and agronomic conditions during growth (Ota et al. 1986), which supports the view that many studies of the biological effects of saponins are difficult to interpret because of the use of ill- or non-defined extracts and crude isolates. It was for this reason that the present study has been conducted using defined Gypsophila, lucerne and soya-bean saponins. Chemically the former is the most complex and is similar to saponins found in 'health' supplements being widely advocated in the orient (Sonnenborn, 1987); the lucerne saponin (containing medicogenic acid as aglycone) is typical of those found in lucerne leaves and tops (Nonaka, 1986), whereas the seeds contain neutral soyasaponins structurally similar to those found in beans such as haricot (Phaseolus vulgaris), kidney (Phaseolus vulgaris) and soya (Glycine max) (Kitagawa, 1984).

In a previous study it was found that the addition of a crude preparation of Gypsophila saponins to a semi-synthetic diet had a detrimental effect on $\mathrm{Fe}$ status in growing rats (Southon et al. 1988), but $\mathrm{Zn}$ status as judged by femur $\mathrm{Zn}$ was unaffected. The present study demonstrated that the amount of Fe absorbed from a test meal could be reduced in the presence of these saponins, which indicates that the effect on Fe status was probably due to reduced Fe absorption. Zn absorption was not affected by the saponins, which is in agreement with our earlier finding of no change in femur $\mathrm{Zn}$. The fact that crude and purified Gypsophila saponins, given at a saponin:Fe molar value of approximately 8 ( $24 \mathrm{mg}$ saponin/meal) were found to give similar values for the proportion of $\mathrm{Fe}$ absorbed from a meal, indicates that the changes in Fe status observed after long-term consumption of the crude extract were due to the saponin fraction of the material.

Lucerne-plant-top saponins, fed at a saponin: Fe value of approximately $8(16 \mathrm{mg} / \mathrm{meal})$, also significantly reduced $\mathrm{Fe}$ absorption, and there were indications that a similar amount 
of soyasaponin I had a marginal effect, which might be important in rapidly growing animals consuming the saponin over a long period. Comparison of the ability of these saponins to increase intestinal permeability in vitro shows a similar pattern of response. Gypsophila saponins produced the greatest rate of decline in transmural potential difference (PD), lucerne-plant-top saponins had a slightly less potent effect, and soyasaponin I decreased the PD only marginally (Johnson et al. 1986; lucerne values, I. T. Johnson, unpublished result).

It was suggested in our previous work (Southon et al. 1988) that saponins may interfere with Fe metabolism, either by forming complexes with the dietary Fe thereby rendering it unavailable for absorption, or by producing changes in mucosal function with long-term consumption, thus reducing the efficiency of nutrient absorption. At first glance, the results from the present study, where saponins were consumed in a single meal, appear to support the first of these two hypotheses. However, the dose-response curve obtained by combining the results from Expts 1 and 2, indicates a more complex mechanism. Combining data this way is not ideal but the resulting curve provides some useful insight into the relation between dietary saponin concentration and the degree of reduction in $\mathrm{Fe}$ absorption. It appears that the effect of Gypsophila saponins plateaux at a saponin:Fe value of approximately 4 (12 $\mathrm{mg}$ saponins/meal), and the observed reduction in $\mathrm{Fe}$ absorption cannot be exaggerated by the addition of more saponin (up to $48 \mathrm{mg} / \mathrm{meal}$ ). This suggests that the reduction in absorption is due to an effect on Fe transport into or across the mucosal cell, rather than a chemical binding in the intestinal lumen, since the latter would be expected to exhibit a more marked concentration dependence (Morck et al. 1983) than was observed in the present study. In vitro-binding studies are necessary to clarify this point. It is possible that even short-term exposure of the mucosal cells to saponin, such as from a single meal, can cause impairment in a sensitive component of the $\mathrm{Fe}$ transport mechanism. As mentioned earlier in the discussion, other studies have clearly shown that some saponins can readily make intestinal absorptive cells permeable in vitro and destroy their capacity for the accumulation of sugars (Johnson et al. 1986); the accumulation and transport of certain other nutrients may therefore be just as readily affected. The absence of any reduction in $\mathrm{Zn}$ absorption from a meal containing saponins demonstrates, however, that any change in intestinal function does not affect the absorption of all mineral nutrients.

The saponin:Fe molar values used in the present study are likely to be higher than would be generally found in the human diet, but the present study gives no indication as to the relative importance of the absolute amounts of saponin and $\mathrm{Fe} v$. the saponin: $\mathrm{Fe}$ molar value in determining the proportion of the mineral available for absorption. Recent calculations indicate a mean daily intake of approximately $20 \mathrm{mg}$ saponins per person (primarily soyasaponins) for the UK, with vegetarians, and people who regularly consume such products as soya-bean-based foods $(370 \mathrm{mg}$ saponins $/ \mathrm{kg})$ and baked beans $(240 \mathrm{mg}$ saponins $/ \mathrm{kg}$ ), having considerably higher intakes, in excess of $100 \mathrm{mg} / \mathrm{d}$ (C. L. Curl, K. R. Price, I. T. Johnson and G. R. Fenwick, unpublished results). The intake of lucerne saponins by man is generally very low but regular consumption of lucerne sprouts, tablets and juice would lead to the consumption of significant amounts of these saponins. It is possible, therefore, that the consumption of foods rich in saponin (which may also contain other inhibitors of mineral absorption such as phytate and tannins) could result in dietary saponin:Fe values demonstrated to influence Fe absorption adversely, particularly when $\mathrm{Fe}$ intakes are marginal.

The identification of the hypocholesterolaemic effects of dietary saponins has led to the suggestion that saponin intakes be increased to regulate plasma cholesterol (Sidhu et al. 1987). However, findings presented in the present study and other studies (Johnson et al. 
1986; Southon et al. 1988), suggest that further work is needed to evaluate more fully the implications of such a dietary change, particularly in relation to intestinal function, and the absorption and utilization of essential minerals.

\section{REFERENCES}

Alvey, N. G., Banfield, C. F., Baxter, T. I., Gower, J. C., Krznowski, W. J., Lane, P. W., Leech, P. W., Nelder, J. A., Payne, R. W., Phelps, K. M., Rogers, C. E., Ross, G. J. S., Simpson, H. R., Todd, A. D., TunnicliffeWilson, G., Wedderburn, R. W. M., White, R. P. \& Wilkinson, G. N. (1977). The GENSTAT Manual. Oxford: Rothamstead Experimental Station, Numerical Algorithm Group Ltd.

Bannerman, R. M., O'Brien, J. R. P. \& Witts, L. J. (1962). Blood, 20 (5), 532-546.

Bondi, A., Birk, Y. \& Gestetner, B. (1973). In Chemistry and Biochemistry of Herbage, p. 511 [I. G. W. Butler and R. W. Bailey, editors]. London: Academic Press.

Cheeke, P. R. (1980). In Leaf Protein Concentrates. pp. 396-414 [L. Telek and H. D. Graham, editors]. Westport, Connecticut: Avi Publishing Co. Inc.

Fairweather-Tait, S. J. \& Wright, A. J. A. (1984). British Journal of Nutrition 51, 185-191.

Gestetner, B. (1971). Phytochemistry 10, 2221-2225.

Gohtani, S., Ohsuka, Y. \& Yamano, Y. (1985). Nippon Nogeikagaku Kaishi 59, 25-30.

Heth, D. A. \& Hoekstra, W. G. (1965). Journal of Nutrition 85, 367-374.

Ireland, P. A. \& Dziedzic, S. Z. (1987). Food Chemistry 23, 105-116.

Johnson, I. T., Gee, J. M., Price, K. R., Curl, C. L. \& Fenwick, G. R. (1986). Journal of Nutrition 116, $2270-2277$.

Kitagawa, I. (1984). Isolation of soya saponins, German Patent no. DE 3400258 Al.

Malinow, M. R., McLaughlin, P. \& Safford, C. (1980). Experientia 36, 562-563.

Morck, T. A., Lynch, S. R. \& Coo, J. D. (1983). American Journal of Clinical Nutrition 37 (3), 416420.

Nonaka, M. (1986). Phytochemistry 25, 73-79.

Ota, T., Hasegawa, T. \& Suzuki, T. (1986). Nippon Nogeikagaku Kaishi 60, 837-839.

Price, K. R., Curl, C. L. \& Fenwick, G. R. (1986). Journal of the Science of Food and Agriculture 37, $1185-1191$.

Price, K. R., Johnson, I. T. \& Fenwick, G. R. (1987). CRC Critical Reviews in Food Science and Nutrition 26, $27-135$.

Sidhu, G. S., Upson, B. \& Malinow, M. R. (1987). Nutrition Reports International 35, 615-623.

Sonnenborn, U. (1987). Deutsche Apotheka Zeitung 127, 433-441.

Southon, S., Johnson, I. T., Gee, J. M. \& Price, K. R. (1988). British Journal of Nutrition 59, 49-55. 